\title{
Memória dos desaparecidos: algumas estratégias visuais ${ }^{1}$
}

\begin{abstract}
Annateresa Fabris ${ }^{2}$
RESUMO: A política de desaparecimentos forçados, implementada pela Junta Militar que governou a Argentina entre 1976 e 1983, tinha como corolário a negação da existência do desaparecido, denominado "não entidade" pelo presidente Jorge Rafael Videla numa coletiva de imprensa, em dezembro de 1979. Essa política de apagamento da existência dos desaparecidos é posta em xeque por ações públicas e intervenções artísticas, que articulam, de diversas maneiras, a problemática da memória.
\end{abstract}

PALAVRAS-CHAVE: Argentina. Ditadura. Desaparecidos. Arte.

ABSTRACT: The politics of forced disappearance, established by the Junta Militar that ruled Argentina between 1976 and 1983, had as a corollary the denial of the desaparecido's existence, defined "non entity" by president Jorge Rafael Videla in a press conference held in December 1979. The attempt to erase the very existence of desaparecidos has been contested by public actions and artistic interventions that enunciate the theme of the memory in many ways.

KEYWORDS: Argentina. Dictatorship. Desaparecidos. Art.

\begin{abstract}
1. Agradeço a colaboração dos funcionários da Biblioteca Nacional Mariano Moreno (Buenos Aires) e da Biblioteca y Centro de Documentación Obispo Angelelli do Centro Cultural de la Memoria Haroldo Conti (Buenos Aires).

2. Docente aposentada da Escola de Comunicações e Artes da Universidade de São Paulo. E-mail: <neapolis@ ig.com.br>.
\end{abstract}


3. A referência a essa documentação foi encontrada na dissertação de mestrado Depois da desaparição: vida, arte e imagem (Argentina 1976-2013), apresentada por Rodrigo Montero na Universidade Federal do Rio Grande do Sul (2013).

4. Conferencia de prensa de Videla 1979, Parte II.

5. Conferencia de prensa de Videla 1979, Parte I.
Em 14 de dezembro de 1979, o presidente da Argentina, Jorge Rafael Videla, participa de uma coletiva de imprensa ${ }^{3}$ num dos salões da Casa Rosada. Trajando um terno cinza, com os cabelos bem penteados, o presidente demonstra ser um verdadeiro ator perante o grupo de jornalistas que participam de um evento que se tornará histórico, em virtude das declarações sobre a "inexistência" dos desaparecidos. José Ignacio López, do El Clarín, usa como pretexto para sua pergunta sobre a situação dos presos sem processo e dos desaparecidos a fala do papa João Paulo II, datada do último domingo de outubro daquele ano, na qual este manifestara sua preocupação com a situação do país sul-americano. Ostentando calma e lançando mão de uma gesticulação exuberante, Videla define, de saída, a atitude do pontífice como congenial à visão do chefe de uma Igreja alicerçada no amor ao próximo e cuja maior preocupação era a preservação da dignidade do homem. Declarando-se católico e partidário do mesmo ideário do papa, o presidente atribui a guerra sangrenta travada contra os grupos armados à defesa dos direitos humanos dos argentinos, ameaçados pelo terrorismo subversivo. Ao mesmo tempo, é estabelecida uma diferença em relação à concepção de direitos humanos enunciada por João Paulo II. Enquanto este só focalizara a questão dos presos e desaparecidos, a Argentina tinha uma visão global do assunto, que abarcava os temas da vida, da liberdade, do trabalho, da família, da moradia etc. Abordando finalmente a problemática dos desaparecidos, Videla faz algumas afirmações surpreendentes pela crueza da exposição. Por sua condição, o desaparecido é "uma incógnita", que não pode merecer um "tratamento especial". Por não possuir "entidade", ele "não existe. Nem morto nem vivo, está desaparecido". ${ }^{4}$

Transmitida ao vivo, a coletiva é editada na difusão feita à tarde e à noite, como lembra Oscar Muiño, um dos participantes do evento. Duas perguntas e as relativas respostas são eliminadas: a de Muiño sobre as forças opositoras à "convergência civil-militar", apregoada pelo governo, e a de López. ${ }^{5}$ Não é improvável que a resposta de Videla sobre os desaparecidos tenha como pano de fundo a visita que a Comissão Interamericana de Direitos Humanos fizera à Argentina em setembro daquele ano, a fim de averiguar denúncias sobre a política governamental. Chefe do golpe de Estado que depusera a presidente María Estela Martínez de Perón, em 24 de março de 1976, o general Videla, designado presidente cinco dias mais tarde, integrava a Junta Militar encarregada do Processo de Reorganização Nacional, ao lado do almirante Emilio Eduardo Massera (Marinha) e do brigadeiro general Orlando Ramón Agosti (Força Aérea). Seu governo, que se estende até 29 de março de 1981, tem como característica principal a violação sistemática dos direitos humanos - supressão da plena defesa, prisões ilegais, sequestros de adultos e crianças, torturas e assassinatos -, acrescida pela ideia de subversão atribuída a toda oposição política e ideológica. Numa entrevista televisiva, transmitida nos Estados Unidos em 14 de setembro de 1977, o presidente havia exposto a questão dos desaparecidos de maneira singular: 
Devemos aceitar como uma realidade que, na Argentina, há pessoas desaparecidas. $\bigcirc$ problema não está em afirmar ou negar essa realidade, mas em saber as razões pelas quais essas pessoas desapareceram. Há várias razões essenciais: desapareceram porque entraram na clandestinidade e se juntaram à subversão; desapareceram porque a subversão as eliminou por considerá-las traidoras de sua causa; desapareceram porque, num confronto, no qual tenha havido incêndios e explosões, o cadáver foi mutilado, tornando-se irreconhecível. E aceito que possa haver desaparecidos por excessos cometidos durante a repressão. Esta é nossa responsabilidade; as outras alternativas não são governadas por nós. E é desta última que nos consideramos responsáveis: o governo tem-se esforçado para evitar que esses casos possam vir a repetir-se. ${ }^{6}$

Defensor até o fim da vida das ações realizadas para poupar a Argentina da ameaça subversiva, Videla é considerado o autor intelectual da ressignificação do termo desaparecido, associado, a partir de suas várias declarações, com os mecanismos utilizados pelo governo para enfrentar os opositores do regime. Ao equiparar o poder do Estado e o dos grupos armados, o general define terrorista não só alguém que utiliza revólver e bombas, "mas também aquele que propaga ideias contrárias à civilização ocidental e cristã" ? Videla, desse modo, justifica o golpe de Estado com o argumento de que a intervenção militar havia sido uma resposta à violência foquista, nascida durante o governo de Arturo Illia (1963-1966), quando as possibilidades de ação política da esquerda haviam se ampliado. Frutos de voluntarismo, as atividades guerrilheiras resultaram numa guerra baseada no mito da revolução, tendo como marcos principais a experiência cubana e a figura de Che Guevara. ${ }^{8}$ As ações guerrilheiras e a atuação paramilitar da Aliança Anticomunista Argentina (1 973-1976) acabam gerando um clima de violência difusa, fazendo com que o golpe de Estado de 1976 encontrasse receptividade em vastos setores da sociedade. Na realidade, a violência guerrilheira começara a ser questionada desde a volta da democracia política em 25 de maio de 1973, com o início do terceiro mandato de Juan Domingo Perón. Grupos de centro-esquerda, o Partido Comunista, agremiações trotskistas e maoístas e a esquerda nacional condenam enfaticamente todo tipo de terrorismo e apoiam a repressão estatal, ressalvando, no entanto, que esta não deveria exceder os marcos legais. A ditadura militar, porém, condensa na guerrilha a personificação da violência, ${ }^{9}$ deixando de lado as ações parapoliciais da Tríplice A, que the servem de inspiração na prática do terrorismo de Estado. ${ }^{10}$

Numa entrevista recolhida por Guido Braslavsky e publicada no livro El dictador: la historia secreta y pública de Jorge Rafael Videla (2001), de María Seoane e Vicente Muleiro, o ex-presidente defende sem meias medidas a prática do desaparecimento:

Não, não se podia fuzilar. Digamos um número, digamos cinco mil. A sociedade argentina mutável, traiçoeira não teria bancado os fuzilamentos: ontem dois em Buenos Aires, hoje seis em Córdoba, amanhã quatro em Rosário, e assim, até cinco mil, dez mil, trinta mil. Não havia outra maneira. Tínhamos que fazê-los desaparecer. É o que mostravam os manuais da repressão na Argélia, no Vietnã. Estivemos todos de acordo. Dar a conhecer onde
6. Desaparecidos durante el Proceso de Reorganización Nacional, s.d.

7. Videla: perfil de un genocida, s.d.

8. Vezzetti (2009, p. 166).

9. Crenzel (2010, p. 76-77, 79).

10. Chefiada por José López Rega, secretário particular de Perón, a Aliança Anticomunista Argentina é responsável pela morte e desaparecimento de quase 700 pessoas vinculadas a grupos considerados marxistas, como organizações guerrilheiras (ERP, Montoneros), a União Cívica Radical e setores de esquerda do movimento peronista. 
11. Desaparecidos durante el Proceso de Reorganización Nacional, s.d. Emilio Crenzel (2010, p. 10) lembra que a ditadura militar combinou quatro estratégias para enfrentar as denúncias sobre os desaparecidos. Optou, a princípio, pela negação dos fatos. Em seguida, apresentou os desaparecimentos como resultado da "guerra" que estava sendo travada no país. Paralelamente a esse reconhecimento, relativizou o número de desaparecidos a fim de desmentir o caráter sistemático e a abrangência nacional e planejada da prática. Finalmente, em setembro de 1982, um mês antes das eleições que puseram fim ao regime, atribuiu a responsabilidade pelo exercício do terrorismo de Estado aos governos constitucionais peronistas que a antecederam.

12. Fundado em 30 de abril de 1977, o grupo é inicialmente composto de catorze pessoas. A partir do terceiro encontro, estabelece-se a prática-símbolo de sua atuação: uma manifestação em frente à sede do governo, às quintas-feiras entre $15 \mathrm{~h} 30$ e $16 \mathrm{~h} 00$.

13. O primeiro nome do grupo era Abuelas Argentinas con Netitos Desaparecidos. O nome atual passa a ser adotado em 1980.

14. Fotógrafos como Helen Zout e Marcos Adandía têm-se debruçado sobre a representação dos rostos de mães de desaparecidos. A primeira é autora do retrato de Adelina Alaye, mãe de Carlos Esteban Alaye, desaparecido em 1977 (c. 20002006); o segundo realizou em 2013 a série "Mãe". Homenagem à atuação das Madres de Plaza de Mayo, a série inclui os retratos de Laura Conte, Elvira Lucía Días de Triana, Aurora Bellochio, Dalia Pollola, Ameris Eugenia Perusini, Josefina Eyriery de Murphy, estão os restos? Mas, o que podíamos assinalar? $\bigcirc$ mar, o Rio da Prata, o Riachuelo? Pensou-se, no devido momento, em dar a conhecer as listas. Mas logo se percebeu: se forem reconhecidos como mortos, virão logo as perguntas a que não se pode responder: quem matou, onde, como. ${ }^{11}$

A entrevista de 1979 traz um elemento adicional: o familiar do desaparecido, consequência palpitante, viva, que o Estado deveria cobrir na medida do possível. Já que o desaparecido não existe, caberá aos familiares cobrar seu aparecimento com vida em ações promovidas pelas associações Madres de Plaza de Mayo ${ }^{12}$ e Abuelas de Plaza de Mayo, ${ }^{13}$ fundadas em 1977. Únicas formas de oposição à ditadura em nome não de uma ideologia partidária ou política, e sim da defesa da liberdade, da vida e dos direitos fundamentais, as duas associações lançam mão de retratos dos desaparecidos, ${ }^{14}$ a fim de comprovar a existência concreta de pessoas, cujas fotografias haviam sido roubadas das casas dos familiares por forças-tarefas militares ou destruídas durante a detenção por agentes governamentais. Em ambos os casos, havia a crença de que o desaparecimento das evidências documentais de uma vida permitiria negar a existência de um determinado indivíduo. Ao desafiarem essa ação do Estado, as mães transformam os próprios corpos em arquivos, "preservando e exibindo as imagens que haviam sido alvo de uma tentativa de apagamento". ${ }^{15}$ As pequenas fotografias penduradas no pescoço podem ser vistas como uma segunda pele, que torna visível o que os militares haviam tentado aniquilar: a relação de parentesco.

Algumas fundadoras da primeira agremiação - Azucena Villaflor de Vicenti, Esther Ballestrino de Carenga e María Ponce de Bianco - sofrem o mesmo destino de seus filhos: a primeira desaparece em 10 de dezembro de 1977; as outras duas, em 17 ou 18 do mesmo mês. Tais episódios não esmorecem a determinação das mães, cujo símbolo era um lenço branco, feito com o mesmo tecido das fraldas infantis - no qual, mais tarde, foram bordados os nomes dos desaparecidos e as datas dos desaparecimentos -, usado na ação mais emblemática: uma marcha silenciosa em volta da Pirâmide de Maio. espetáculo dessas mulheres idosas, que transforma um processo de luto interrompido num discurso de resistência contra o terror, é colocado por Diana Taylor sob o signo de um ritual performático realizado no coração do centro político e financeiro da Argentina. ${ }^{16}$

Conscientes de que sua batalha tinha uma forte carga simbólica, os dois grupos recorrem ao auxílio de artistas visuais, organizando várias ações públicas, entre as quais o siluetazo, ${ }^{17}$ realizado em 21 e 22 de setembro de 1983. As Madres e Abuelas de Plaza de Mayo propõem que Rodolfo Aguerreberry, Julio Flores e Guillermo Kexel revejam a ideia de elaborar milhares de silhuetas dos desaparecidos dotadas de traços individuais. A ideia de utilizar silhuetas foi sugerida a Aguerreberry, Flores e Kexel pelo cartaz Cada dia em Auschwitz (1978), do artista polonês Jerzy Shapski, reproduzido no El Correo de la Unesco 
de outubro de 1978. A obra, que fazia referência aos mortos de Auschwitz, era constituída de 24 fileiras de pequenas silhuetas de mulheres, homens e crianças, acompanhadas pelo seguinte texto:

Cada dia em Auschwitz morriam 2370 pessoas, exatamente o número de figuras aqui reproduzidas. $\bigcirc$ campo de concentração funcionou durante 1688 dias, e este é precisamente o número de exemplares impressos desse cartaz. Ao todo morreram no campo cerca de quatro milhões de seres humanos. ${ }^{18}$

Outro antecedente pode ser encontrado nas bandeiras e estandartes usados pela Associação Internacional de Defesa dos Artistas Vítimas de Desaparecimento no Mundo (AIDA), fundada em Paris em 1979. Em suas manifestações, a AIDA representava os desaparecidos como bustos sem rosto ou grupos de silhuetas. ${ }^{19}$

Contornos das formas vazias de corpos em tamanho natural são desenhados de maneira rudimentar por voluntários em folhas de papel, afixadas posteriormente em muros, vitrines, árvores e suportes verticais, com o objetivo de afirmar a presença dos desaparecidos e de questionar a ditadura a partir do campo artístico. Embora os corpos sejam genéricos, a inscrição do nome do desaparecido e da data de desaparecimento no interior da forma vazia é uma maneira de singularizar cada biografia É significativo que nessa representação substitutiva do corpo violentado, as mães e as avós não tenham optado pela colocação das silhuetas no chão, já que seu lema era "Aparición con vida". ${ }^{20}$ Colocar as silhuetas no chão equivaleria a equipará-las a túmulos, e não era isso que as duas organizações pleiteavam publicamente. ${ }^{21}$

$\bigcirc$ jogo entre generalização e singularização, que está na base do silvetazo, será também determinante na instalação 30.000 (1999-2009), concebida por Nicolás Guagnini para o Parque da Memória - Monumento às Vítimas do Terrorismo de Estado, instalado nas margens do rio da Prata. ${ }^{22}$ A obra é assim descrita pelo artista:

Meu projeto consiste de 25 prismas retos retangulares de planta quadrada. Essa espécie de conjunto de vigas de metal verticalmente ordenadas sobre uma grade forma um cubo. Sobre as peças que compõem o cubo está pintada a imagem de um rosto obtida a partir de uma fotografia projetada diagonalmente sobre um vértice. Trata-se de um retrato de meu pai, que minha avó usava nas manifestações. $\bigcirc$ tipo de resolução da fotografia em preto e branco [é] absoluto. À medida que o espectador se desloca em volta do cubo começa a perceber fragmentos e, inclusive, repetições e distorções do rosto, que aparece e "desaparece" alternativamente na paisagem do rio. Existe um ponto de vista ideal que permite a reconstrução do rosto, da memória. ${ }^{23}$

A instalação de Guagnini parte de um fato autobiográfico: o sequestro do pai, em dezembro de 1977, mas atinge uma dimensão coletiva ao receber o título de 30.000. $\bigcirc$ artista, desse modo, transforma o próprio luto num luto coletivo pelos desaparecidos, confrontando o espectador com uma ocorrência política
Lilia Jons de Orfanó, Sara Ludmer de Steimberg, Alba Eugenia Martino e de Adelina Morel (irmã de uma desaparecida).

15. Taylor (2013, p. 249250).

16. Taylor (2013, p. 240241).

17. O nome original da ação era "silueteada". O uso do sufixo "azo" acaba por destacar a ação coletiva mais do que a silhueta em si mesma. Cf. Fiel (2013, p. 215).

18. El antecedente de Shapski, 2008.

19. Longoni (2010, p. 5152).

20. Montero (2010, p. 2931, 35).

21. Por seu caráter simbólico, a ação de setembro de 1983 tem um efeito multiplicador. Silhuetas são utilizadas em inúmeras manifestações ocorridas em Buenos Aires: Silhuetas no Obelisco (8-9 de dezembro de 1983), quando silhuetas são pintadas no chão da rotunda com os dizeres "Aparición con vida de los desasparecidos"; Segundo Siluetazo (9-10 de dezembro de 1983); Marcha do Nunca Más (20 de setembro de 1984); Marcha das silhuetas vermelhas (21 de setembro de 1989); Marcha das silhuetas brancas (29 de março de 1990), em que silhuetas tridimensionais são dispostas, de maneira intercalada, entre as Madres de Plaza de Mayo; Décima Marcha da Resistência (6 de dezembro de 1990), na qual são usadas silhuetas tridimensionais feitas com jornais. Fora da Argentina, pode ser destacado o siluetazo realizado em Santiago do Chile em 26 de agosto de 1988 , durante o qual foram colocadas silhuetas de desaparecidos diante da Catedral, acompanhadas de 
nomes e dos dizeres "Você me esqueceu? Sim -não". Mais recentemente, podem ser lembradas as comemorações relativas ao massacre de Margarita Belén, ocorrido em 13 de dezembro de 1976 na região do Chaco. Em 4 de junho de 2010, dia em que teve início o processo pelo massacre, o Grupo Cultura X Justicia organizou uma silueteada em Resistência, a fim de "celebrar um momento de esperança e justiça", nos dizeres de Cecilia Fiel (2013, p. 216218). A autora destaca ainda que o $34^{\circ}$ aniversário do massacre (2011) foi lembrado por cartazes nos quais era reproduzido um desenho representando torsos amarrados, de olhos vendados e boca aberta, com marcas vermelhas no peito, alusivas aos fuzilamentos de desaparecidos, de autoria de Miguel Molfino, ex-preso político.

22. Inaugurado em 2007, o Monumento às vítimas do terrorismo de Estado é constituído de quatro estelas, dispostas de maneira a evocar uma gigantesca ferida aberta, nas quais foram e continuam a ser inscritos os nomes das vítimas da repressão política na Argentina entre 1969 e 1983 . Pelo parque, estão espalhadas esculturas de artistas argentinos e internacionais como Roberto Aizenberg, León Ferrari, Claudia Fontes, Magdalena Abakanoviz, Dennis Oppenheim, Marie Orensanz e William Tucker. No passeio ao longo do rio, o Grupo de Arte Callejero (GAC), surgido em 1997, instalou os Cartazes da memória, que traçam um panorama da história recente da Argentina. A narrativa destaca episódios de violência anteriores à ditadura militar, como as execuções de Trelew, levadas a cabo pela Marinha, em 22 de agosto de 1972 , contra um grupo de dezesseis militantes de organizações guerrilheiras que haviam se ren- inquestionável. $\bigcirc$ fato de o observador ter que se deslocar no espaço para conseguir ver o rosto, o qual desaparece tão logo ele volte a se movimentar, dando lugar a manchas e fragmentos pretos, é uma forma de envolvê-lo diretamente na questão dos desaparecimentos forçados por obra do "terrorismo de Estado" e de contrapor a memória ao desconhecimento arvorado pelo governo. As repetições e distorções, assinaladas por Guagnini, podem ser interpretadas como remissões a um retrato coletivo, à negação da ausência propugnada pelo governo e à prática da tortura que visava destroçar corpos e mentes.

Na apresentação do projeto, o artista acaba por vincular seu trabalho à ação das organizações de direitos humanos, da qual surgiu:

[... ] a imagem paradigmática da situação dos desaparecidos e símbolo inequívoco reconhecível, inclusive por aqueles que "não sabiam nada": os retratos em preto e branco, muitas vezes fotos de identidade, reproduzidos ad infinitum e carregados, colados e publicados por familiares e militantes. Rostos de jovens, cujos penteados e roupas envelheceram, mas que, a partir dessas fotografias, olham, de maneira acusadora e indelével, para o não falado, o não esclarecido. ${ }^{24}$

Convidado a participar do projeto do Parque da Memória, Christian Boltanski sugeriu que, em lugar de um monumento tradicional, fosse publicado em algum jornal um anúncio diário lembrando uma das vítimas. Qual não foi sua surpresa ao saber que essa ideia já era exercida na Argentina desde 1988, por meio da prática dos recordatorios. ${ }^{25}$ A partir da publicação do recordatorio de Laura Estela Carlotto em 25 de agosto de 1988, o jornal Página/ 12 dedica espaço a um anúncio peculiar que homenageia o desaparecido no aniversário de seu sequestro, a fim de perpetuar sua memória e provar sua existência, em contraposição à política negacionista do Estado. A ideia não partiu do jornal, fundado em fins de maio de 1987, conhecido por uma postura ideológica de centro-esquerda e integrado por pessoas provenientes de organizações de defesa dos direitos humanos, mas de Estela de Carloto, líder das Abuelas de la Plaza de Mayo, que desejava lembrar o $10^{\circ}$ aniversário da morte da filha. Publicado gratuitamente em atenção à figura de Carlotto, o recordatorio de Laura Estela ocupava o canto esquerdo inferior da página 8, dividindo o espaço com as notícias do dia. A gratuidade do anúncio atrai os familiares de outros desaparecidos, levando o jornal a publicar uma média diária de dois ou três recordatorios. ${ }^{26}$

formato do recordatorio evoca de imediato os cartazes fúnebres do sul da Itália, que anunciam a morte de uma pessoa e, frequentemente, a consternação da família com a perda irreparável. Luis Gusmán, por sua vez, aproxima essa prática do "direito à morte escrita", vigente em Atenas desde a primeira metade do século IV a. C., pelo qual todo cidadão deveria dispor de um epitáfio com os dados da filiação e o lugar do falecimento. ${ }^{27}$ Não existe um padrão fixo para os recordatorios; a legenda em memória do desaparecido pode vir acompanhada de vários dispositivos discursivos. Em alguns, há salmos, em outros, poesias, em outros, ainda, uma breve história do desaparecido. $\bigcirc$ traço 
comum a todos eles é a denúncia, expressa em enunciados elípticos como "ausência forçada", "preso-desaparecido", "te arrancaram do nosso lado". A denúncia pode abarcar os agentes do terrorismo de Estado, denominados "assassinos". Muitos recordatorios, mesmo invocando Deus ou uma crença religiosa, trazem uma marca peculiar: a ausência da ideia de reconciliação, visível em frases como "Nem esquecimento nem perdão", "Não esquecem nem perdoam teus filhos, teus pais", "Não ao ponto final", "Não à obediência devida", "Não ao indulto". ${ }^{28}$

Celina Van Dembroucke coloca os recordatorios sob o signo de uma contradição, por estarem situados no cruzamento com outros gêneros anteriores: obituário, anúncio de pessoas desaparecidas e denúncia política. Enquanto os obituários remetem ao tributo a um ente querido, os anúncios de pessoas desaparecidas expressam a esperança de encontrálas com vida. A mesma relação de contraposição e comunhão pode ser encontrada nos textos: o obituário é um ato privado que se torna público, lido, no entanto, como um reconhecimento entre familiares e conhecidos. $\bigcirc$ anúncio de pessoas desaparecidas, por sua vez, é um ato claramente público, que se dirige a toda a sociedade, na esperança de que alguém tenha notícias sobre quem está sendo procurado. Não se pode esquecer ainda de que a publicação dos recordatorios corresponde a uma denúncia pública, já que, várias vezes, são mencionados os nomes dos responsáveis pelos desaparecimentos. Mesmo quando isso não é possível, a simples publicação do anúncio é um ato de acusação contra a ditadura militar. Se, nessa perspectiva, o recordatorio desempenha suas funções de maneira complexa, é inegável, porém, que ele é um campo de memória ativa, uma ferida aberta, a indicar a inexistência de um efetivo trabalho de luto. ${ }^{29}$

Um breve texto de Sigmund Freud sobre a guerra e a morte ajuda a esclarecer melhor uma das motivações dos recordatorios. Ao refletir sobre a atitude das pessoas perante a morte, Freud sublinha a presença de um mecanismo peculiar: cria-se uma visão acrítica do defunto, a quem são perdoados erros, falhas e equívocos, como demonstram de sobejo os louvores dos obituários e das pedras tumulares. Quando a morte atinge uma pessoa querida, os entes mais próximos sentem-se desamparados, pois com ela são sepultadas esperanças, aspirações e alegrias, dando lugar a uma recusa ao consolo e à ideia de substituição. ${ }^{30}$ No caso em análise, não apenas os recordatorios, mas as próprias descrições feitas pelos familiares dos desaparecidos trazem a marca dessa visão peculiar. Valores morais, virtudes, a sensibilidade diante da miséria e da injustiça, uma atitude solidária para com o próximo são amplamente destacados, sem que haja qualquer menção a filiações políticas. Emilio Crenzel encontra uma justificativa adicional para essa atitude, da qual surge a figura da "vítima inocente". Lançar mão dessa figura permitia dotar de legitimidade as reivindicações junto às autoridades e às organizações de direitos humanos e, ao mesmo tempo, evitar problemas políticos e o isolamento da família diante do próprio círculo de parentes e conhecidos. ${ }^{31} \mathrm{Se}$ isso explica o tom sentimental de muitos recordatorios, é importante não esquecer dido com a condição de que suas vidas fossem poupadas; o massacre de Ezeiza, ocorrido em 20 de junho de 1973, quando do regresso de Perón ao país, ocasionado pelo enfrentamento entre duas organizações peronistas: Montoneros e CGT; e a atuação da AAA. Questões políticas e econômicas, associadas à ação sistemática de extermínio implementada pelo governo militar, são apresentadas sucessivamente ao observador, o qual se depara, quase no final do trajeto, com assertivas sobre a permanência de um legado repressivo, mesmo nos governos democráticos posteriores à ditadura. O percurso termina com a placa Aqui moram genocidas, que lista nomes e endereços de participantes da repressão e mapeia a localização dos Centros Clandestinos de Detenção (CCD).

23. Guagnini (2010, p. 130).

24. Guagnini (2010, p. 130)

25. Montero (2011, p. 74).

26. Dembroucke (2013, p. 121-122). Atualmente, a prática deixou de ser diária, como comprova uma pesquisa feita entre 27 de setembro e 8 de outubro de 2015 .

27. Gusmán (2005).

28. Frases extraídas de fotos encontradas na internet, s.d.

29. Dembroucke (2013, p. 122-123).

30. Freud (1982, p. 74).

31. Crenzel (2010, p. 6970). 
32. Montero (2013, p. 108109); Gusmán (2005).

33. Vales (2008).

34. Giunta (2009, p. $197-$ 200).

35. Montero (2013, p. 132). outro dado: os desaparecidos são mortos sem sepultura. A ausência do corpo leva - familiar do desaparecido a conviver simultaneamente com a negação da vida e a negação da morte. Instaura-se, assim, "uma presença latente", associada à esperança de, um dia, conseguir realizar o ritual de passagem com a cerimônia de sepultamento. Sem viver uma situação de luto efetivo, o familiar experimenta "uma sensação de ausência" insolúvel, que não the permite aceitar adequadamente a perda sofrida. A dimensão do "presente que não se resolve" está na base das reivindicações dos recordatorios e da negação de qualquer possibilidade de reconciliação ou perdão para os algozes. ${ }^{32}$

Se bem que utilizem elementos considerados estéticos por Gusmán poemas, letras de canções, citações literárias ou dos Evangelhos -, os recordatorios não são obras de arte, nem mesmo conceitual, como pretendem alguns artistas. ${ }^{33}$ São uma maneira político-afetiva de perpetuar a memória dos desaparecidos, confrontando a sociedade argentina com o trauma provocado pela repressão oficial. De outra natureza é a operação que está na base da instalação coletiva Identidade, apresentada no Centro Cultural Recoleta, de Buenos Aires, entre 19 de novembro e 8 de dezembro de 1998. Contando com - apoio das Abuelas de Plaza de Mayo, 13 artistas envolvidos na causa dos direitos humanos (Carlos Alonso, Nora Aslan, Mireya Baglietto, Remo Bianchedi, Diana Dowek, León Ferrari, Rosana Fuertes, Carlos Gorriarena, Adolfo Nigro, Luis Felipe Noé, Daniel Ontiveros, Juan Carlos Romero e Marcia Schvartz) conceberam uma árvore genealógica peculiar, integrada pelas fotografias de casais desaparecidos, intercaladas por um espelho e informações biográficas. O primeiro objetivo da proposta era localizar crianças nascidas em cativeiro, que poderiam deparar com a própria história familiar ao visitarem a mostra, cuja localização num centro cultural não era casual. Este tornava-se o cenário de uma informação ativa e, logo, um espaço de transformação, cuja eficácia repousava no impacto visual provocado no espectador. As fotografias ampliadas para proporcionar uma comunicação imediata e os espelhos concebidos como dispositivos reprodutores envolviam os visitantes na experiência de uma situação presente. Afinal, seus rostos passavam a integrar o drama dos desaparecidos, atestando o acerto estético-político da proposta, que colaborou no processo de devolução de identidade a crianças sequestradas pela ditadura. ${ }^{34}$

Em 1995, um novo ator político entra na cena dos direitos humanos, a organização H.I.J.O.S, sigla de Hijos por la Identidad y la Justicia contra el Olvido y el Silencio. Como o próprio nome indica, trata-se de uma organização integrada por filhos adolescentes ou ingressando na vida adulta de desaparecidos, assassinados ou exilados pela ditadura militar. Como aponta Rodrigo Montero, o surgimento de H.I.J.O.S significou o ingresso, como agente de sentido, daquela parcela de vítimas que, até então, havia ficado de fora do trabalho de construção da memória. Até aquele momento, essa tarefa estivera nas mãos das mães e também de irmãos, amigos e colegas. Com a nova associação, a sociedade começava a ser confrontada "com um novo sentido das vítimas do terrorismo de Estado: o desaparecido como pai". ${ }^{35}$ 
Desde sua fundação, o grupo dá vida a manifestações públicas ruidosas denominadas "escrachos", definidos por Taylor "uma forma de performance-guerrilha", "protestos carnavalescos", 36 que reúnem de 300 a 500 pessoas, com o objetivo de denunciar aos vizinhos a presença, num determinado endereço, de um agente da repressão, indultado pelo presidente Carlos Menem (1989-1999), ou de um centro clandestino de tortura. Altamente teatrais para que as pessoas tomem conhecimento da denúncia, os escrachos são bem organizados. Bonecos gigantes e, não raro, enormes cartazes com as fotos dos desaparecidos acompanham os manifestantes que pulam e cantam pelas ruas. Vans equipadas com alto-falantes lembram aos vizinhos os crimes cometidos naquela região. Em geral, um mês antes da ação, o grupo investiga o bairro em que esta terá lugar, mostrando fotografias dos agentes da repressão, dando informações sobre eles e colando suas fotos em locais públicos e nos muros. No momento do escracho, com a ajuda de artistas ativistas, como o Grupo de Arte Callejero, os organizadores colocam placas de sinalização de ruas com fotos dos acusados, pintam, diante de sua residência ou escritório, seu nome e seus crimes, a fim de alertar a sociedade de que as violações dos direitos humanos não foram punidas nem terminaram. ${ }^{37}$

Se bem que a organização reconheça explicitamente sua dívida para com as Madres e as Abuelas de Plaza de Mayo, sua atuação reflete mudanças políticas e geracionais. Enquanto as duas primeiras focavam suas reivindicações nos desaparecidos, os membros de H.I.J.O.S tornam públicos os nomes dos repressores e dos organismos envolvidos na Guerra Suja. Ao protesto e ao luto ritualístico do passado, contrapõem atos carnavalescos ou de execração pública. $\bigcirc$ uso das fotografias é ampliado por eles, já que abarca os repressores, obrigados a destruir as próprias imagens, a modificar a aparência e a inventar uma nova identidade. Se não existem fotografias recentes disponíveis, os membros do grupo seguem furtivamente suas presas e tiram fotos. Desse modo, "orquestram uma guerra de relações públicas contra seus inimigos, do mesmo modo como os militares convenceram a população em geral de que suas vítimas eram guerrilheiros perigosos" ${ }^{38}$

A questão da fotografia é central para H.I.J.O.S, não apenas para denunciar a identidade dos agentes da repressão, mas também para evidenciar o trauma de uma perda que não thes permite ter fotos da família completa. Entre 1996 e 2001, um grupo de filhos de desaparecidos durante a Operação Independência (5 de fevereiro de 1975-28 de setembro de 1977), realizada na província de Tucumán, com o objetivo de reprimir a guerrilha do ERP, aceita participar do projeto do fotógrafo Julio Pantoja. Indignado com a eleição do general Antonio Domingo Bussi - que fora interventor na região entre 1976 e 1978 - a governador da província, o fotógrafo dá início a um trabalho, definido por Gabriel Gatti como uma "identidade construída na ausência". ${ }^{39}$ A estratégia de representação é discutida por Pantoja com os participantes da série Os filhos, Tucumán vinte anos depois. Vários deles optam por posar com fotos da mãe ou do
36. Taylor (2013, p. 232).

37. Taylor (2013, p. 233).

38. Taylor (2013, p. 240 , 254-256).

39. Gatti (2008). 
40. Gatti (2008, p. 120-121).

41. Quieto (2011, s.p.).

42. Dillon (2007, s. p.).

43. Apud Longoni (2011, s.p.).

44. Longoni (2011, s. p.). pai desaparecidos, já que estas eram as únicas formas de contato com eles. Surgem, assim, imagens que exibem "a permanente e ambígua presença" da ausência dos pais desaparecidos, 40 afirmando uma determinação ao mesmo tempo subjetiva e política. Esse grupo de retratos, com efeito, transforma os filhos em vetores de uma memória familiar, interrompida pela brutalidade da repressão, e social, haja vista as imagens dos pais funcionarem como símbolo de uma história de luta e violência que a sociedade argentina não pode e não deve esquecer.

Uma das integrantes da agremiação, Lucila Quieto, realiza um dos trabalhos mais instigantes com a problemática da memória dos desaparecidos no ensaio Arqueologia da ausência (1999-2001). Como a própria artista declara, o que motivou o trabalho foi o desejo de abordar a perda da identidade como "perda de uma parte da cultura". Não foi fácil chegar à determinação de trabalhar com a própria história, de "transmitir a angústia diante da falta de imagens", finalmente suprida pela construção/reconstrução de "certas realidades ausentes". ${ }^{41}$

A questão da identidade é um elemento de fato central na proposta de Quieto, filha natural de Carlos Alberto, militante montonero sequestrado em 20 de agosto de 1976. Nascida depois do desaparecimento do pai, a artista é registrada como filha de mãe solteira, vindo a incorporar o sobrenome Quieto aos 17 anos. A essa reconstrução da própria identidade, marcada forçosamente pela ausência, ${ }^{42}$ soma-se a constatação de que não existia nenhuma imagem que a retratasse na companhia do pai. Algumas estratégias visuais são analisadas: recortar e reorganizar os rostos fundidos do pai e da mãe a partir de retratos de identidade e elaborar uma enorme árvore genealógica com as fotografias de todos os desaparecidos e de seus filhos. Surge, finalmente, a ideia que estrutura Arqueologia da ausência: colocar-se numa fotografia do pai, a fim de construir a imagem "que havia sempre buscado, tornando-me parte dela". ${ }^{43}$

$\bigcirc$ processo de fotomontagem utilizado é bastante simples. Convertidas em diapositivos, as fotografias ampliadas do pai são projetadas numa parede; a seguir, a artista intervém com a própria presença na projeção, conseguindo, assim, a fotografia que faltava no álbum de família. "Ao colocar-se entre o projetor e a parede, o efeito foi prodigioso" - escreve Ana Longoni, que assim prossegue sua análise - "[...] quando a pele se evidencia e se torna, por um instante, tela, ou antes, suporte para que essas imagens de outro tempo se tornem corpo, ocorre o encontro". ${ }^{44}$ Entusiasmada com os resultados alcançados, Quieto resolve estender o processo a outros militantes de H.I.J.O.S para inserir sua geração numa narrativa coral, capaz de conferir um significado mais amplo a um trauma coletivo. Vários filhos respondem a seu chamado, que resulta em 13 histórias contadas, por meio de 150 imagens. Cada filho interessado em possuir uma imagem singular coloca à disposição da artista o que tem à mão: uma fotografia, 10 fotografias, caixas com 200 imagens... Depois de ver a fotografia ampliada da mãe na parede, um amigo desiste do projeto. No caso de Walter e do pai Néstor Antonio Meza Niella, Quieto recorre a periódicos da década 
de 1970 para encontrar possíveis imagens dos dois. Realizado ao longo de dois anos, o processo de construção de fotografias impossíveis não é visto de maneira exclusivista por ela; ${ }^{45}$ numa entrevista concedida em 2011 , afirma preferir que as pessoas se apropriem dele para construir a própria história, o próprio álbum familiar, sem depender de sua intervenção. ${ }^{46}$

Compostas de maneira artesanal, as imagens de Arqueologia da ausência exibem a materialidade das fotografias que serviram de ponto de partida para a configuração das diferentes narrativas. Margens irregulares, dobras, rasgos, riscos, entre outros, alteram a superfície da imagem final (Carlos Alberto Quieto/ Lucila, Néstor Edgardo Morales/Demián, Manuela Santucho/Diego, por exemplo). Outros elementos geram estranhamento nessas fotografias singulares, sobretudo a diferença de escala entre as presenças do passado e as inserções do presente, erodindo, segundo Ana Amado, toda pretensão de verossimilhança no jogo concebido pela artista. ${ }^{47}$ Tendo em vista essa precariedade buscada, é possível aventar a hipótese de que Quieto tenta se aproximar da estética da fotografia doméstica, caracterizada, não raro, por enquadramentos desequilibrados, borrões, iluminação desigual, sem que isso ponha em xeque a comunicação das experiências íntimas do núcleo familiar. ${ }^{48}$

A evidenciação do processo de montagem introjeta uma temporalidade peculiar nas imagens do ensaio fotográfico. Regido por uma forte tensão entre passado e presente, o encontro entre pais e filhos é reportado pela artista a um "terceiro tempo", a um tempo "inventado, onírico, ficcional", a partir do qual é possível subverter, graças aos instrumentos da arte, um destino imposto por outrem. Do encontro entre "o que foi" e "o que é" surge "o que já não pode ser", sem que isso exclua a possibilidade da "cerimônia do encontro" simbólico entre pais e filhos. ${ }^{49}$ Em alguns momentos, esse encontro parece apontar para um desejo de recuperar um topos fundamental da fotografia doméstica: a reconstituição dos sinais que testemunham as "correntes subjacentes" dos relacionamentos familiares específicos. A pergunta formulada por Charlotte Cotton a esse respeito - "Quem fica ao lado de quem num retrato de grupo?"50 - não deixa de ecoar em algumas poses escolhidas pelos protagonistas de Arqueologia da ausência. Não é incomum aparecerem no ensaio cenas que remetem à infância. Numa das fotografias, o corpo agigantado da filha, no qual é projetada a imagem de uma criança correndo, situa-se entre os pais, como que para recriar a cena de uma intimidade perdida (Marta Taboada/Marta). Um recurso semelhante é mobilizado na montagem em que a filha Verónica aparece ao lado da mãe Graciela Valdueza, que segura um bebê no colo. Em outra composição, vê-se uma cena familiar projetada no corpo da filha (Alberto Evaristo Comas/Lucía). A projeção de um busto infantil no corpo da filha adulta (Marta Taboada/Marta) ou de uma figura feminina que se ergue como um nume tutelar sobre a intimidade dos pais (María Teresa Trotta e Roberto Castelli/Verónical são outros recursos de que se serve Quieto para construir suas cenas de uma infância impossível. A problemática da infância está também presente numa das composições mais emblemáticas do
45. Ana Longoni (2011, s. p.) destaca o uso das estratégias visuais de Quieto em dois filmes feitos por militantes de H.I.J.O.S: Los rubios, de Albertina Carri (2003), e $M$, de Nicolás Prividera (2007). Carri recorta fotografias para elaborar a recomposição de uma cena ficcional ideal, inclusive bucólica e infantil, em virtude do uso de lápis de cor. Prividera fotografa-se ao lado da mãe, tendo a mesma idade, a mesma altura e o mesmo tamanho. Para uma análise mais aprofundada da questão, ver Armas (2012).

46. Enríquez (2011).

47. Amado (2009, p. 175).

48. Cotton (2010, p. 137).

49. Longoni (2011, s.p.).

50. Cotton (2010, p. 138). 
51. Arfuch (2005, p. 89-90).

52. Fortuny (2008, p. 14).

53. Longoni (2011, s.p.). conjunto, em que se detecta a procura de um jogo temporal acurado: a fotografia do momento atual dá a impressão de que Marta deseja reassumir o lugar que ocupara nos braços da mãe Marta Taboada, já que seu tamanho é igual ao do bebê.

A fusão dos corpos do passado e do presente não obedece a um padrão único: pode haver a sobreposição de rostos (Guillermo Perot/Guillermina, Carlos Alberto Quieto/Lucila), a colocação das imagens do passado e dos corpos do presente lado a lado (Manuela Santucho/Diego, Guillermo Perot/Guillermina), a aparição fantasmática do desaparecido Uuan Patricio Moroni/Paula) e a inscrição de um corpo em outro (Marta Taboada/Marta, Alberto Evaristo Comas/ Lucía), gerando tatuagens peculiares. Uma das imagens mais contundentes nesse sentido é a que mostra uma jovem com o corpo recoberto por fotografias do álbum de família, dando a sensação de uma imersão num passado fantasmático, feito tão somente de representações de cenas íntimas, do qual não deseja se separar Uuan Carlos Arroyo/Marina). É significativo que, em alguns momentos, surjam sombras a testemunharem a existência de um espaço não preenchido entre passado e presente, de uma distância que o encontro simbólico não consegue disfarçar (Marta Taboada/Marta). Graças a esses recursos, a artista nada mais faz do que sublinhar que o "terceiro tempo" é fruto de uma trama na qual história e ficção se cruzam e se imbricam, conferindo uma identidade narrativa, um ponto de articulação tanto a indivíduos quanto a comunidades. ${ }^{51}$

Natalia Fortuny resume, com muita propriedade, o significado do título do ensaio:

Um arqueólogo trabalha com restos. Com indícios, vestígios, marcas do passado que se descobrem no presente. Um fotógrafo produz esses vestígios. Assim, Lucila Quieto indaga nesses restos ao mesmo tempo em que os causa: cerca de imagens cada ausência, precisamente para que venha à luz em cada fotografia. Sem pretensão de verdade-objetiva ou verdade-documento, antes com a certeza de que cada foło reconstrói o mundo que mostra, ao mesmo tempo em que o interpela. ${ }^{52}$

As imagens de Arqueologia da ausência acabam por desempenhar vários papéis. São uma maneira de elaborar o trabalho de luto por meio de uma "pequena sutura simbólica, ao mesmo tempo íntima e coletiva". ${ }^{53}$ São obras de arte, marcadas por um viés anacrônico e por um cruzamento fecundo entre história e imaginário. São imagens-testemunho da existência dos desaparecidos, exibidas em manifestações de H.I.J.O.S, com a expectativa de gerar alguma informação. São biografias peculiares, em que o individual e o coletivo se encontram com o objetivo de produzir vestígios de um passado inconcluso. Por seu intermédio, as pequenas narrativas particulares se integram na corrente da história recente da Argentina, numa demonstração de que é possível personalizar um acontecimento político graças à apresentação de situações inseridas numa temporalidade impossível, mas nem por isso menos real. Nas mãos de Quieto e dos jovens que aderiram a seu projeto, participando ativamente dele, a existência configura-se 
como resultado de uma escrita, como um mecanismo retórico que gera um modelo próprio: "a vida como produto da narrativa". 54 As vidas truncadas dos desaparecidos servem de alimento para a definição das identidades dos filhos, num processo de criação/autocriação em constante devir, no qual a sensação de perda é, de certo modo, compensada pela definição de novas possibilidades políticas e afetivas.

Ao ser publicado em livro, o ensaio fotográfico incorpora pequenas legendas sobre pais e filhos. ${ }^{55}$ Os primeiros são definidos por nome, sobrenome, profissão, militância política e dados sobre o desaparecimento. ${ }^{56}$ As informações sobre os segundos são mais enxutas: nome, atividade atual e pouco mais. Ana Longoni detecta nessa atitude um sentido militante: o corpo do filho torna-se um suporte para que o pai emerja das sombras e se torne visível, palpável. ${ }^{57}$ Quieto corrobora essa leitura quando atribui a falta do sobrenome dos filhos ao desejo de coletivizar a história e quando aproxima suas montagens dos recordatorios. Tanto num como no outro, o que importa é a figura do desaparecido e não da pessoa que promove sua lembrança. A questão, porém, não é tão simples, já que a artista vê em seu ensaio a reparação de uma obsessão: a obtenção da foto que faltava no álbum de família.

terceiro tempo não deixa de ser o momento de definição de uma nova identidade. Quieto demonstra isso num depoimento citado por Ana Amado. Seu afastamento de H.I.J.O.S é explicado em termos bastante contundentes. Embora reconheça a importância da atuação do grupo, ele faz parte de uma etapa superada. "Não posso continuar a ser filha por toda a vida", declara, ao defender um espaço próprio:

Quero fazer outras coisas, poder contar outras coisas, ser eu mesma a partir de outro lugar, a partir do que sou para além de minha história e de minha identidade. [...] Chegou o momento de ocupar outro lugar, de deixar o lugar de vítima. [...] Ser o "filho de" é muito pesado, arcar com a história dos pais... Agora acabou. [...]. . $^{58}$

Essa declaração taxativa não impede, contudo, que Quieto volte a enfocar a questão dos desaparecidos e a mergulhar, uma segunda vez, na história familiar. É o que comprova a exposição Filiação, realizada em março de 2013 no Centro Cultural da Memória Haroldo Conti (Buenos Aires). Integrada por três conjuntos de imagens e por um vídeo, a mostra coloca-se de novo sob o signo da busca do pai. A algumas imagens de Arqueologia da ausência, segue-se a série Lugares de memória (2008-2012), constituída por fotografias de campos de concentração, usados pela repressão, e do rio da Prata. ${ }^{59}$ Há uma razão pessoal para essa escolha. $\bigcirc$ rio interessa à artista porque é provável que o pai tenha sido arremessado em suas águas ou ter estado num dos "voos da morte". Com as fotografias dos campos, pretende "observar e registrar os lugares por onde passaram meu pai ou meu tio. 60 Entrar num lugar (um espaço físico) que tem o peso dos corpos que estiveram lá e registrar os rastros do que ficou". ${ }^{61}$
54. Arfuch (2005, p. 61).

55. Na exposição Arqueologias, realizada em abril de 2007, que constava de diferentes trabalhos da artista não havia nenhuma identificação para as imagens de Arqueologia da ausência.

56. Em 2011, aparecem as seguintes definições: montonero (Carlos Alberto Quieto, Juan Patricio Maroni, Guillermo Perot, María Teresa Trotta/Roberto Castelli, Néstor Antonio Meza Niella); tupamaro (María Elsa Martínez Gorreiro); militante do PRT-ERP (Manuela Santucho); membro da Frente 17 de Outubro (Juan Carlos Arroyo); militante político (Luis María Gemetro, Marta Taboada); militante sindical (Néstor Edgardo Morales); vítima do "massacre de Fátima" (Alberto Evaristo Comas); sem militância específica (Graciela Valdueza/Fernando Villanueva). Denomina-se "massacre de Fátima" o sequestro e execução de 20 homens e 10 mulheres, ocorridos em 20 de agosto de 1976 , na pequena localidade da província de Buenos Aires. Para não deixar vestígios, os corpos foram dinamitados.

57. Longoni (2011, s.p.).

58. Apud Amado (2009, p. 175).

59. A problemática dos locais de detenção está bastante presente na fotografia argentina. Depois do ensaio O matadouro (1998), que Natalia Fortuny (2013, p. 135-136) considera um "sutil trabalho alegórico sobre o dispositivo estatal de desaparecimento de pessoas da última ditadura, especificamente sobre suas maquinarias de tortura e morte", Paula Lutringer dá início, em 2000, à série $O$ lamento dos muros, dedicada aos Centros Clandestinos de Detenção. Acompanhadas do testemunho das víti- 
mas da ditadura, as fotografias geram um "mapa de memória singular", situado entre o visível e o dizível. Outro exemplo é Garage Azopardo (2010), em que Dani Yako registra o lugar em que ele e a companheira, militantes da Federação Juvenil Comunista, estiveram presos durante quatro dias em setembro de 1976 (Garage Azopardo y la perdida de la identidade, 2011). Também Marcelo Brodsky debruçou-se sobre o tema com a série Memória em construção (2005), dedicada à Escuela Mecánica de la Armada (ESMA). A temática do rio, por sua vez, está presente nas imagens em que Brodsky registrou o Parque da Memória e na série Palavras (1985-1995).

60. A artista refere-se ao advogado Roberto Quieto, que começara sua militância na Federação Juvenil Comunista, em fins da década de 1960. Foi um dos fundadores das Forças Armadas Revolucionárias (FAR), tendo sido responsável pela fusão da organizaç̃o com os Montoneros em 1973. Foi detido em 28 de dezembro de 1975 , durante o governo de María Estela M. de Perón. Foi visto no CCD Campo de Mayo. Segundo um telegrama da embaixada norte-americana, estava vivo em 26 de janeiro de 1976. Acredita-se que o exército o tenha mantido em vida até 1978. Em 3 de janeiro de 1976 , os montoneros instauraram um processo revolucionário contra ele, que se concluiu em 14 de fevereiro com as penas de degradação $\mathrm{e}$ morte pelos crimes de deserção em operação e delação. Cf. Los desaparecidos: Roberto Quieto (s. d.); Pastoriza (2005).

61. Entrevista a Lucila Quieto, 2013.

62. Entrevista a Lucila Quieto, 2013.
Oterceiro conjunto, Família Quieto, elaborado entre 2012 e 2013, é constituído de colagens feitas a partir de fotografias da família paterna, do filho, dos filhos dos primos e do único tio ainda vivo (José Luis). A ideia "da transmissão, do genético" está na base da nova série em que a artista se propõe a "armar traços familiares através da tua/sua família. Construir uma imagem da vida que meu pai não pôde ter. Desde seu irmão mais velho até meu filho". ${ }^{62} \bigcirc$ artifício da construção das imagens impõe-se de imediato, uma vez que Quieto utiliza vários recursos, entre os quais a mistura de traços fisionômicos, para construir um novo álbum de família. A presença da ausência, tão determinante em sua trajetória, volta a ser utilizada como mecanismo retórico, num trabalho que pode ser definido "um luto pensado em imagens", a "reconstrução da família que restou". 63 A problemática da morte aparece de maneira direta numa das imagens da série, na qual flores são sobrepostas a um retrato infantil de Carlos Alberto Quieto. Jordana Blejmar propõe uma associação da composição elaborada pela artista com adornos como flores, mechas de cabelos e outros objetos aplicados a fotografias de defuntos em fins do século XIX, com o objetivo de reforçar "o poder memorialístico da imagem fotográfica". A colagem é também analisada pela autora a partir da ideia de Geoffrey Batchen de que a memória está sempre em estado de ruína, já que lembrar algo implica deslocá-lo de seu lugar de origem. Nessa perspectiva, as flores desempenhariam um papel duplo: evocação do estado ruinoso da memória e ênfase dos elos existentes entre vida e morte. ${ }^{64}$

Um traço novo surge nessa etapa: a idealização de Arqueologia da ausência é temperada pela presença de algumas imagens grotescas da família. Numa das composições, pessoas sorridentes, em cujos corpos estão inscritas algumas silhuetas pretas, têm diante de si caveiras desenhadas de maneira rudimentar e um recorte fotográfico de homens atirando. $\bigcirc$ aspecto grotesco da colagem, como resultado de duas instâncias opostas, é realçado pelo rosto marcado como um alvo, levando o espectador a conferir um significado preciso à presença dos atiradores. $\bigcirc$ motivo da caveira sorridente está também presente como sobreposição na fotografia de duas figuras masculinas numa paisagem ensolarada e pedregosa. Em outra colagem, a desproporção entre corpos e cabeças faz dos modelos seres quase monstruosos, em total desacordo com a ideia de harmonia que emana de todo álbum de família. Os papéis familiares, eternizados pela fotografia doméstica, são sujeitos nesse caso a uma interrogação irônica sobre o significado da normalidade, gerando uma "intensa sensação da incapacidade das convenções sociais de manter a ordem". ${ }^{65}$ A presença de selos em algumas composições pode ser atribuída a um fato afetivo. Carlos Alberto Quieto tinha um álbum de selos que Lucila gostava de folhear porque "tinha a ver com o manual". Como o álbum era um dado "tangível" de sua existência, a filha tinha a possibilidade de estabelecer um contato tátil com ele, de "tocar algo que ele também havia manipulado". ${ }^{66}$ A colagem em que a fotografia de Lucila em uniforme escolar é acompanhada de um corpo masculino desdobrando-se em vários momentos, de uma borboleta e de um selo com o perfil da América do Sul 
ganha um significado profundamente pessoal quando se pensa nessa referência. Isso não exclui a possibilidade de uma leitura política, como a proposta por Rodrigo Montero, o qual chama a atenção para o destaque dado à Argentina no selo, que poderia funcionar como uma alegoria do Estado e da Nação assombrando a infância com a violência e o terror do desaparecimento. ${ }^{67}$

Engajada numa nova associação - CDH (Colectivo de Hijos Huérfanos Producidos Cientificamente por el Genocidiol -, a artista compartilha com seus companheiros o interesse pela colagem como ferramenta que permite "armar, desarmar, buscar e juntar situações que têm a ver tanto com o arquivo fotográfico (documento) quanto com a fantasia". A questão da imagem que possibilita "dizer, expressar, refletir, construir a história pessoal"68 enlaça-se com o trabalho levado a cabo em Arqueologia da ausência. Nos dois casos, o elemento mobilizador está na fotografia, no álbum de família, pois os filhos só dispõem de imagens dos pais desaparecidos para construir sua memória pessoal. Apesar de continuar a cavoucar nos vestígios de uma experiência traumática, Quieto tem uma percepção lúcida de que o presente demanda uma nova concepção de engajamento. Por isso, não se sente "uma continuação" do pai ou de seus companheiros. As discussões do presente são outras, exigindo a "recomposição de histórias e laços sociais que se haviam rompido" e a "inclusão de um monte de setores que estavam afastados e espezinhados". 69

Se é evidente, nesse tipo de declaração, que os filhos não pretendem ficar presos ao passado, mas construir uma nova história e, por meio dela, a própria história, é também evidente que o instrumento escolhido, a fotografia, é uma maneira de afirmar diretamente a existência dos desaparecidos. Graças a ela, as figuras dos desaparecidos demonstram que seu lugar não está no arquivo. Estendendo a toda a produção de Quieto o que Cecília Sosa escreveu sobre Arqueologia da ausência, poder-se-ia dizer que os desaparecidos voltam continuamente, convidando a sociedade argentina a indagar como "as comunidades se constituem através de contatos afetivos com o passado." 70 Seja como testemunho, seja como criação artística, a fotografia é um elemento fundamental na manutenção de uma memória que continua a assombrar o presente, solicitando que a ausência não se transforme em vazio. Ao registrar o corpo dos que tiveram sua existência negada pelo terrorismo de Estado, a fotografia como marca indicial afirma a presença do passado no presente. A ideia de Quieto de que "só desaparece quem não deixa vestígios"71 é um convite a continuar a indagar o que foi feito não de maneira melancólica, e sim propositiva, transformando o passado em algo ainda vivo e palpitante.
63. Índice (2013, p. 26).

64. Blejmar (2013, p. 175176). A autora, na realidade, não é de todo fiel ao pensamento de Batchen. Este afirma que a memória fica presa num enigma: a passagem do tempo que torna a memória possível e necessária é igualmente responsável por seu enfraquecimento e morte. As flores de cera que adornam $\mathrm{Em}$ paz (c. 1890), que serviu de ponto de partida para a reflexão sobre esse tipo de memória, lembram, a um só tempo, pétalas reais e a "inevitável falta de impressão que a recordação pode apenas adiar". Por isso, $\mathrm{Ba}$ tchen afirma que o artefato não representa a memória, mas sua "dissolução inescapável” (2004, p. 77-78).

65. Cotton (2010, p. 138).

66. Pereyra (s.d.).

67. Montero (2013, p. 141).

68. Entrevista a Lucila Quieto, 2013 .

69. Entrevista a Lucila Quieto, 2013.

70. Sosa (2014, p. 47).

71. Apud Longoni (2011, s. p.). 


\section{REFERÊNCIAS}

LIVROS, ARTIGOS E TESES

AMADO, Ana. La imagen justa: cine argentino y política (1980-2007). Buenos Aires: Colihue, 2009.

ARFUCH, Leonor. El espacio biográfico: dilemas de la subjetividad contemporánea. Buenos Aires: Fondo de Cultura Económica, 2005.

BATCHEN, Geoffrey. Forget me not: Photography and Remembrance. Amsterdam: Van Gogh Museum; Nova York: Princeton Architectural Press, 2004.

BLEJMAR, Jordana. La Argentina en pedazos: los collages fotográficos de Lucila Quieto. In: BLEJMAR, Jordana et al. (org.). Instantáneas de la memoria: fotografía y dictadura en Argentina y América Latina. Buenos Aires: Libraria, 2013, p. 173-193.

COTTON, Charlotte. A fotografia como arte contemporânea. Trad. Maria Sílvia Mourão Netto. São Paulo: WMF Martins Fontes, 2010.

CRENZEL, Emilio. La víctima inocente: de la lucha antidictatorial al relato del Nunca más. In: CRENZEL, Emilio (org.). Los desaparecidos en la Argentina: memoria, representaciones e ideas (1983-2008). Buenos Aires: Editorial Biblos, 2010, p. 65-83.

DILLON, Marta. Lucila Quieto: Arqueologías. In: QUIETO, Lucila. Arqueologías. Buenos Aires: Fondo Nacional de las Artes, 2007, s. p.

FIEL, Cecilia. Representar y conmemorar: en torno a la masacre de Margarita Belén. In: OLIVERAS, Elena (org.). Estéticas de lo extremo: nuevos paradigmas en el arte contemporáneo y sus manifestaciones latinoamericanas. Buenos Aires: Emecé, 2013, p. 197-225.

FORTUNY, Natalia. Palabras fotográficas: imagen, escritura y memoria. In: BLEJMAR, Jordana et al. (org.). Instantáneas de la memoria: fotografía y dictadura en Argentina y América Latina. Buenos Aires: Libraria, 2013, p. 133-156.

FREUD, Sigmund. Considerazioni attuali sulla guerra e la morte. Caducità. Roma: Editori Riuniti, 1982.

GATTI, Gabriel. El detenido-desaparecido: narrativas posibles para una catástrofe de la identidad. Montevideo: Ediciones Trilce, 2008.

GIUNTA, Andrea. El arte de la restitución. Sobre la exposición Identidad presentada en Berlín en 2004. In: Poscrisis: arte argentino después de 2001. Buenos Aires: Siglo Veintiuno, 2009, p. $197-200$. 
GUAGNINI, Nicolás. 30.000. In: HOCHBAUM, Nora; BATTITI, Florencia (org.). Monumento a las victimas del terrorismo de Estado. Parque de la Memoria. Buenos Aires: Consejo de Gestión Parque de la Memoria Monumento a las Victimas del Terrorismo de Estado Gobierno de la Ciudad Autónoma de Buenos Aires, 2010, p. 130-133.

Índice. In: Filiación. Buenos Aires: Centro Cultural de la Memoria Haroldo Conti, 2013, p. 26.

LONGONI, Ana. (Sobre Lucila Quieto, Arqueología de la ausencia) Apenas, nada menos. In: QUIETO, Lucila. Arqueología de la Ausencia. Buenos Aires: Casa Nova Editores, 2011, s.p.

. Fotos y siluetas: dos estrategias contrastantes en la representación de los desaparecidos. In: CRENZEL, Emilio (org.). Los desaparecidos en la Argentina: memoria, representaciones e ideas (1983-2008). Buenos Aires: Editorial Biblos, 2010, p. 43-63.

MONTERO, Rodrigo. Da silbueta ao álbum de família: arte e práticas artísticas na construção de memórias da ditadura argentina. Porto Alegre: Instituto de Artes/Universidade Federal do Rio Grande do Sul, 2010.

. MONTERO, Rodrigo. Depois da desaparição: vida, arte e imagem (Argentina 19762013). Porto Alegre: Instituto de Artes/ Universidade Federal do Rio Grande do Sul, 2013.

QUIETO, Lucila. [Declaração]. In: Arqueología de la ausencia. Buenos Aires: Casa Nova Editores, 2011, s.p.

SOSA, Cecilia. Queering acts of mourning in the aftermath of argentina's dictatorship: the performances of blood. Woodbridge: Tamesis, 2014.

TAYLOR, Diana. O arquivo e o repertório: performance e memória cultural nas Américas. Trad. Eliana Lourenço de Lima Reis. Belo Horizonte: Editora UFMG, 2013.

VAN DEM BROUCKE, Celina. Las fotografías carnet de los desaparecidos en los recordatorios de Página/12. In: BLEJMAR, Jordana et al. (org.). Instantáneas de la memoria: fotografía y dictadura en Argentina y América Latina. Buenos Aires: Libraria, 2013, p. 119-132.

VEZZETTI, Hugo. Dos cuestiones en las políticas actuales de la memoria en la Argentina. In: MUDROVCIC, María Inés (org.). Pasados en conflicto: representación, mito y memoria. Buenos Aires: Prometeo Libros, 2009, p. 157-171.

SITES

El antecedente de Shapski. Página/12, Buenos Aires, 21 set. 2008. Disponível em: <www. pagina12.com.ar/diario/suplementos/espectaculos/subastas/11368-3515-2008-09-21-html>. Acesso em: 16 out. 2015.

Conferencia de prensa de Videla 1979 Parte I. Disponível em: <http://www.dailymotion.com/ video/x6ndw7conferencia-de-prensa-de-videla-197_news>. Acesso em: 3 maio 2015. 
Conferencia de prensa de Videla 1979 Parte II. Disponível em: <http://www.dailymotion.com/ video/x6ndgzconferencia-de-prensa-de-videla-197_news>. Acesso em: 3 maio 2015.

Desaparecidos durante el Proceso de Reorganización Nacional. Disponível em: <es.wikipedia. org/.../Desaparecidos_durante_el Proce...>. Acesso em: 4 maio 2015.

Los desaparecidos: Roberto Quieto. Disponível em: <www.desaparecidos.org/arg/victimas/ quieto>. Acesso em: 15 jun. 2015.

Entrevista a Lucila Quieto (2013). Disponível em: <http://conti.derhuman.jus.gov.ar/2013/04/ noticias-entrevista-lucila-quieto.shtml>. Acesso em: 16 jun. 2015.

ENRÍQUEZ, Mariana. Reencuentros. Página/12, Buenos Aires, 18 dez. 2011. Disponível em: <www.pagina12.com.ar/diario/suplementos/radar/9-7565-2011-12-18-html>. Acesso em: 15 jun. 2015.

FORTUNY, Natalia. La foto que le falta al álbum. Memoria familiar, desaparición y reconstrucción fotográfica en la obra de dos artistas argentinos. In: XII Jornadas Nacionales de Investigadores en Comunicación. Disponível em: <sm000153.ferozo.com/memorias/ pdf/2008Foponencia\%20fortuny,\%20natalia,\%20ok.pdf>. Acesso em: 15 jun. 2015.

Garage Azopardo y la pérdida de la identidad. Clarín, Buenos Aires, 19 fev. 2011. Disponível em: <www.clarin.ar/politica/Garage-Azopardo-perdida-identidad-_0_430757020.html>. Acesso em: 12 out. 2015.

GUSMÁN, Luis. Como la marea. Página/12, Buenos Aires, 22 dez. 2005. Disponível em: <www. pagina12.com.ar/.../9-60797-2005-12-22-html>. Acesso em: 5 maio 2015.

LARRALDE ARMAS, Florencia. Apuntes sobre la fotografía en el cine de los HIJOS. Un estudio sobre los filmes Los Rubios, M y Papá Iván. Revista Afuera/Estudios de Crítica Cultural, Buenos Aires, n. 11, maio 2012. Disponível em: <wwwrevistaafuera.com/articulosphp?1998\&nro=11>. Acesso em: 2 maio 2015.

PASTORIZA, Lila. La "traición" de Roberto Quieto (2005). Disponível em: <www.elortiba.org/ pdf/lucharmada6.pdf>. Acesso em: 15 maio 2015.

PEREYRA, Laura A. Tercer tiempo. Disponível em: <www.global16.com/r2/post-46>. Acesso em: 18 jun. 2015.

VALES, Laura. Registros de la ausencia. Página/12, Buenos Aires, 24 ago. 2008. Disponível em: <https://www.pagina12.com.ar/diario/elpais/1-110291-2>. Acesso em: 5 maio 2015.

Videla: perfil de un genocida. Disponível em: <http://www.telam.com.ar/notas/201305/17991videla-perfil-de-un-genocida.html>. Acesso em: 4 maio 2015.

Artigo apresentado em 29/08/2016. Aprovado em 07/12/2016. 